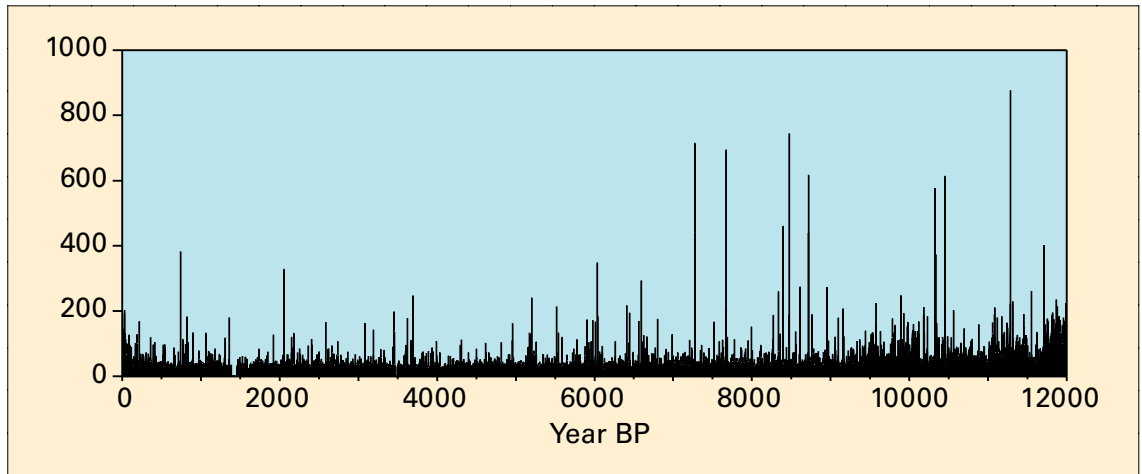

Figure 2: Holocene record of volcanic sulfate (anomalies from background variations) recorded in the GISP2 ice core from Summit, Greenland (Zielinski et al., 1994).

able after a few years, so individual explosive eruptions only contribute short-term variability to the spectrum of Holocene climate. However, if eruptions were more frequent in the past, or if they happened to occur in clusters, it is possible that the cumulative effect of eruptions could have persisted for longer, resulting in decadal- to multi-decadal scale impacts. Such effects would be enhanced if the initial cooling led to feedbacks within the climate system, such as more persistent snow and sea-ice cover, which would raise the surface albedo and possibly alter the atmospheric circulation. Indeed, the non-seasalt sulfate record from the GISP2 ice core does suggest that there were periods of more frequent explosive eruptions in the past, such as in the period 9500-11500 calendar years BP (Fig. 2) (Zielinski et al., 1994) Furthermore, in the early Holocene there were many large volcanic signals, greater in magnitude than those recorded after the eruption of Tambora (1815), the largest eruption in recent centuries. Of course, a larger sulfate signal might simply mean that the eruption event was closer to the deposition site, so we do not have a definitive long-term record of the magnitude of overall volcanic forcing, or more specifically, of atmospheric optical depth and its distribution latitudinally (cf. Roberston et al., 2001). Energy balance and GCM studies that have parameterized the effects of explosive volcanism and solar forcing over recent centuries suggest that these two factors can explain most of the variability of temperatures over the last millennium (e.g. Crowley, 2000). It therefore seems likely that they have also played a significant role in overall Holocene forcing on inter-annual to century timescales.

\section{RefERENCES}

Alley, R.B., Mayewski, P.A., Sowers, T., Stuiver, M., Taylor K.C. and Clark, P.U., 1997: Holocene climatic instability: a prominent, widespread event $8200 \mathrm{yr}$ ago. Geology 25: 483-486.

Barber, D.C., Dyke, A., Hillaire-Marcel, C., Jennings, A.E., Andrews, J.T., Kerwin, M.W., Bilodeau, G. McNeely, R., Southon, J., Morehead, M.D. and Gagnon, J.M., 1999: Forcing of the cold event of 8,200 years ago by catastrophic drainage of Laurentide lakes. Nature 400: 344-348.

Bradley, R.S., 2003: Climate forcing during the Holocene. In: Global Change in the Holocene: approaches to reconstructing fine-resolution climate change. A.W. Mackay, R.W. Battarbee, H.J.B. Birks \& F. Oldfield (eds.). Arnold, London (in press)

Robock, A., 2000: Volcanic eruptions and climate. Reviews of Geophysics 38: 191-219.

Zielinski, G., Mayewski, P.A., Meeker, L.D., Whitlow, S., Twickler, M.S., Morrison, M., Meese, D.A., Gow A.J. and Alley, R.B., 1994: Record of explosive volcanism since 7000 B.C. from the GISP2 Greenland ice core and implications for the volcano-climate system. Science 264: 948-952.

\title{
Tephra, a Powerful Tool for Precision Dating and Correlation
}

\author{
Jon R. Pilcher ${ }^{1}$, Ray Bradley ${ }^{2}$, Lesleigh Anderson ${ }^{2}$ and Pierre Francus ${ }^{2}$ \\ 1School of Archaeology and Palaeoecology, Queen's University, Belfast, Northern Ireland; j.pilcher@qub.ac.uk \\ ${ }^{2}$ Department of Geography, University of Massachusetts, Amherst, MA, USA; rbradley@geo.umass.edu; land@geo.umass.edu; \\ francus@geo.umass.edu
}

\section{Summary}

Icelandic tephra is proving to be a valuable new chronological and stratigraphical tool for the palaeoenvironmentalist in NW Europe. It is particularly useful in the historic period where radiocarbon dating seldom provides adequate precision, and also in situations where sediments are unsuitable for such dating because of variable marine influence.

\section{Geographical Distribution and Temporal Range}

Tephra is the air-fall component of ejecta from a volcano. Tephras can be found embedded in deposits in many areas of the world, in fact there is probably no part of the globe from which such deposits are absent. The use of Icelandic tephras in stratigraphic studies and as a dating tool is well developed in NW Europe. Tephra particles are usually less than 100 micrometers (commonly 20-60 $\mu$ in diameter) and are glass (Fig. 1). In all the studies described here, the tephra is invisible in the cores and sections and must be detected microscopically. The ideal medium for detection of minute traces far from the parent volcano is a highly organic matrix such as peat. The tephra can be released by burning sub-samples of the organic material and dissolving the peat ash in dilute acid. The

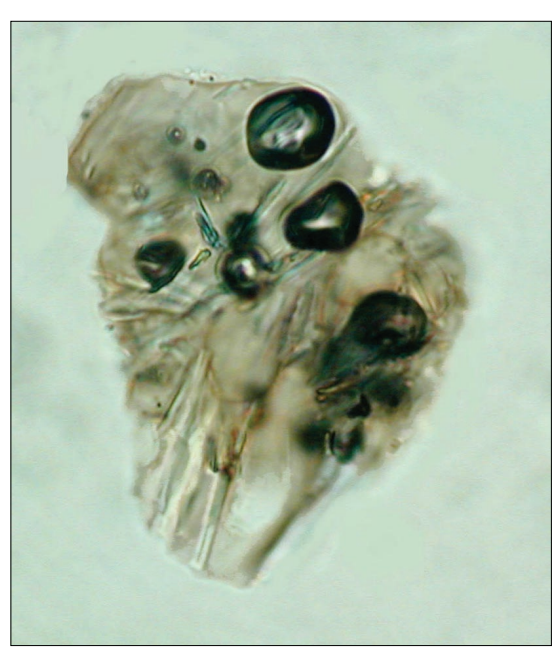

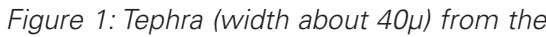
AD 1158 eruption of Hekla found in peat from the Lofoten Islands. 
clean material can then be mounted in resin and examined under a microscope. This process is described in Pilcher and Hall (1992). Where the matrix has more than about $1 \%$ mineral content, separation of the tephra is more difficult. Sieving between mesh sizes of 26 and $75 \mu$ will retain most of the tephra and will remove sand and clay. If this is not adequate, then a heavy liquid separation has proved successful (Turney, 1999).

\section{Tephra in Arctic Norway}

Last year, a team from the University of Massachusetts, Amherst and
The area has been subject to major relative sea level changes, with many lakes passing through both marine and fresh water episodes. This poses special constraints on the value of radiocarbon dating.

Following the successes of using Icelandic tephra for chronological control in Ireland (Pilcher et al., 1996; Hall and Pilcher, 2002), Scotland (Dugmore et al., 1995), Germany (van den Bogaard and Schminke, 2002) and other areas distant from Iceland, this technique was selected for dating in Lofoten. As there had been no tephra work done in this area before, we select-

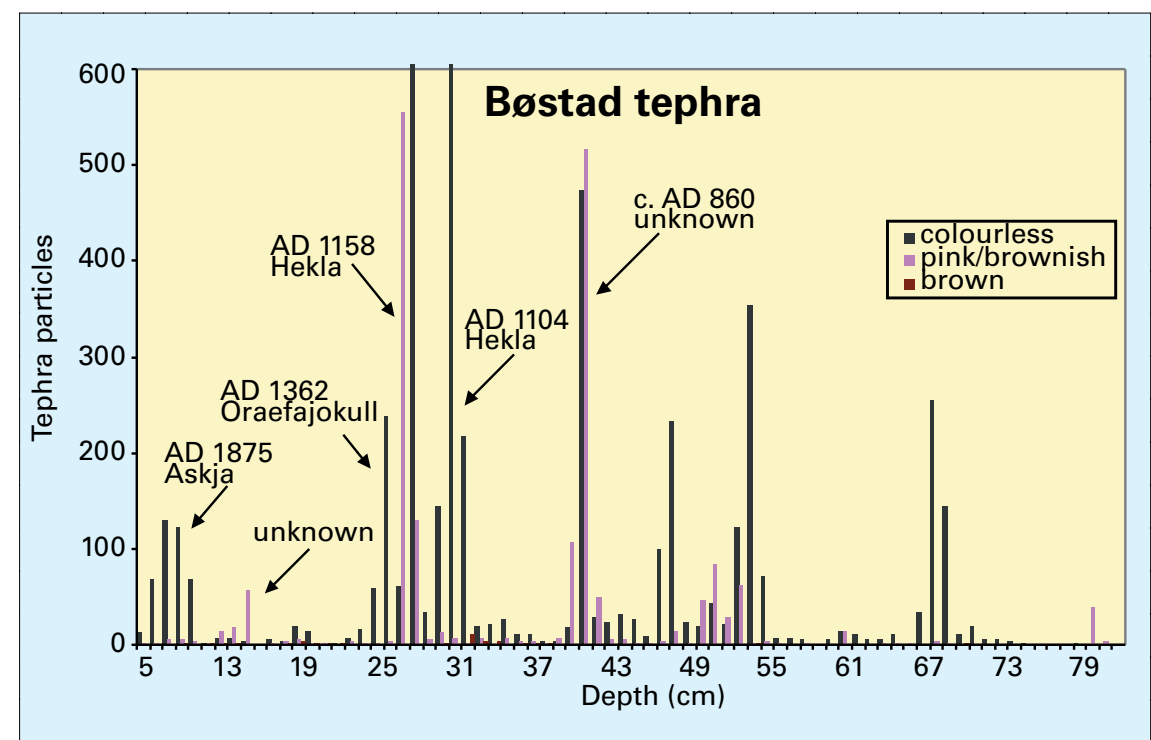

Figure 2: Stratigraphic sequence of tephra analysis from a peat bog at Bøstad in the Lofoten Islands. Marked layers have been identified by matching microprobe-determined major element chemistry of the tephra with that of historically dated layers from Iceland and elsewhere. Not all layers have yet been determined.

Queen's University, Belfast carried out exploratory fieldwork in the Lofoten Islands off the northwest coast of Norway, just inside the Arctic Circle. We hypothesize that the Lofoten islands are sensitive to changes in ocean currents (fluctuations of the North Atlantic Drift) and to circulation shifts associated with different modes of the North Atlantic circulation.

At present, the outer islands are bathed in waters that reach $+11^{\circ} \mathrm{C}$ in summer $\left(+5-6^{\circ} \mathrm{C}\right.$ in winter) in spite of their high latitude. Changes in the strength and/or position of this warm water tongue will drastically affect the Lofoten environment. The islands have many deep fresh water lakes, fjords and peat bogs with Holocene records. to lake basin. Even better, we will also be able to correlate with other work on a whole transect along the Atlantic seaboard of Europe at key dates such as 2310 BC (Hekla 4).

\section{Chemical Fingerprinting of Tephras}

Simple preparation by burning is not suitable when chemical analysis is required, as burning changes the glass chemistry. In this case, the organic matter is dissolved in a chemical oxidizing mixture as described by Dugmore et al. (1995) The tephra recovered from the acid treatment is washed and mounted for electron microprobe analysis.

Volcanic systems vary in their chemistry. The products of individual volcanoes may also differ and in some cases, such as in Iceland, many individual eruptions are geochemically distinct. Because the differences between eruptions are quite subtle, wavelength dispersive microprobe analysis is used rather than the simpler and more commonly available energy dispersive analysis. It is usual to analyze between 10 and 20 individual tephra fragments.

Type material comes from profiles examined in Iceland. Many have been analyzed (e.g. Larsen andThorarinsson, 1977; Haflidason et al., 2000), many more remain to be examined. Analyses are stored in the Tephrabase Data Bank and are available to all researchers at this URL: http://www.geo.ed.ac.uk/ tephra/tbasehom.html

Not all tephras are chemically distinct. For example, the AD 1947 and AD 1510 tephras from Hekla are very similar, as are those of Hekla 4 (2310 BC) and Hekla 5 (5990 BC). Normally other stratigraphic information allows us to discriminate between these pairs of tephras.

\section{Tephra for Correlation Between Cores, Sample Sites and Regions}

A typical eruption lasts for days or perhaps even months, a very short time in relation to the accumulation of typical terrestrial and 
marine stratigraphic sequences. Thus, an ash layer forms a tightly defined time-marker.

One of the perennial problems of working in bog and lake deposits is correlation from one core to another. Analyzing tephra can be an ideal technique in these circumstances, since the horizontal layers are so sharply defined.

\section{Tephra as a Taphonomic Guide}

Tephra has so far been under-utilized as a taphonomic guide. As the tephra fall is assumed to occur at least within a single year, we can make a good assessment of post depositional processes by looking at the vertical spread of the tephra in a sediment core. Spreading can also be the result of delayed deposition of particles stored for more or less time in the watershed or the lake basin. As the particle size of the typical tephra layer is of the same order as that of pollen, for example, it can suggest the extent to which pollen and other micro- fossils may have been moved vertically in the sediment profile. For example, if the tephra were spread over $5 \mathrm{~cm}$, there would be little point in undertaking a pollen study at a resolution of $1 \mathrm{~cm}$.

\section{Tephra as a Chronology}

Tephrochronology consists of knowing when eruptions took place and then of tying a tephra fall to a particular eruption by its chemistry. From about AD 1100, a well-recorded chronology of calendrical accuracy exists for Iceland. Before settlement in Iceland, we are dependent on dating tephra layers by independent means. Radiocarbon dating of a terrestrial peat allows a precise date to be applied to tephra-bearing low-organic lake sediments or marine to brackish water sediment that is unsuitable for precision radiocarbon dating. One of the ongoing projects is to use the calendrical precision of the new NGRIP Greenland ice core to produce dates for the geochemically typed tephra layers it contains.

\section{AcKnOWLedgements}

The Lofoten Islands project is supported by a National Science Foundation grant (Paleoclimatology Program) to the University of Massachusetts.

\section{REFERENCES}

van den Bogaard, P. and Schminke, H.-U., 2002: Linking the North Atlantic to central Europe: a high resolution Holocene tephrachronological record from northern Germany. Journal of Quaternary Science 17: 3-20.

Haflidason, H., Eiriksson, J. and van Kreveld, S., 2000: The tephrochronology of Iceland and the North Atlantic region during the Middle and Late Quaternary: a review. Journal of Quaternary Science 15: 3-22.

Hall, V.A. and Pilcher, J.R., 2002: Late quaternary Icelandic tephras in Ireland and Great Britain: detection, characterization and usefulness. The Holocene 12: 223-230.

Larsen, G. and Thorarinsson, S., 1977: H4 and other acid tephra layers. Jokull 27: 29-47.

Pilcher, J.R., Hall, V.A. and McCormac, F.G., 1996: An outline tephrochronology for the north of Ireland. Journal of Quaternary Science 11: 485-494.

For full references please consult: www.pages-igbp.org/products/newsletters/ref2003_2.htm

\title{
Simulating the Climate of the Last Millennium
}

\author{
Martin Widmann ${ }^{1}$ and Simon F.B. Tetr ${ }^{2}$ \\ ${ }^{1}$ Institute for Coastal Research, GKSS Research Centre, Geesthacht, Germany; widmann@gkss.de \\ ${ }^{2}$ Hadley Centre for Climate Prediction and Research, Met Office, Bracknell, UK; simon.tett@metoffice.com
}

\section{Introduction}

Climatic changes during the last thousand years have received great interest. Uncertainty in climate reconstruction is smaller than in earlier periods and the external forcing factors of the climate system are relatively well known, making comparisons with 20th century climate well suited to assessing the influence of human activities. Numerical modelling complements the efforts to reconstruct past climates from proxy records. The goals of paleoclimate modelling are to reduce uncertainties in climate reconstructions through consistency tests with evidence from proxy data, to validate climate models, to provide hypotheses on the climatic evolution at locations or variables not covered by proxy data, and to improve process understanding. The latter should include distinguishing be- tween internal variability and the effects of varying external forcings, and understanding feedback mechanisms.

\section{Types of Climate Models and Simulations}

The simplest climate models are zero- or one-dimensional energy balance models (EBMs), which have low computational costs and clear links between simulated processes and climate. At the other end of the spectrum are quasi-realistic, computationally expensive, general circulation models (GCMs), which usually feature sub-models for the atmosphere, the ocean and the sea ice on 3-dimensional grids with typical horizontal spacings of a few hundred kilometers and 15-100 vertical levels. GCM components for the carbon cycle, chemical processes, land ice and vegetation dynamics are currently under development. In between EBMs and GCMs are a variety of models with varying numbers of dimensions and complexity, for instance, earth system models of intermediate complexity (EMICs), which describe the atmosphere and ocean dynamics in less detail but which place more emphasis on the role of vegetation and chemical processes in the climate system. Climate models are mainly used in two different ways. In equilibrium experiments, the forcing factors for the climate system, such as solar irradiance, the atmospheric composition, or the earth's orbit, are held constant but may vary between different runs. These simulations represent the mean climate and the statistics of internal climate variability. Transient, forced simulations also include the climate response to time-varying forcings using historical estimates. 